\title{
Die diagnostische Zuverlässigkeit des Neuraminsäurel Protein-Quotienten im Fruchtwasser als Indikator für die
} fetale Reife

\begin{tabular}{|l|l|l|}
\hline B. & Beate & Kästner $^{\mathrm{a}}$ \\
\hline H. & & Schenk $^{\mathrm{b}}$ \\
\hline W. & & Weise $^{\mathrm{a}}$ \\
\hline
\end{tabular}

${ }^{a}$ Klinik für Gynäkologie und Geburtshilfe II (Vorst.: Prof. Dr. sc. med. W. Weise) ${ }^{\text {b Institut }}$ für Pathologische Biochemie der Medizinischen Akademie Magdeburg (Vorst.: Prof. Dr. sc. med. H. Schenk)

Dr. Beate Kästner, Klinik für Gynäkologie und Geburtshilfe, Klinikbereich II, Medizinische Akademie Magdeburg, Leipziger Straße 44, D-0-3090 Magdeburg

Der bisher nicht im Fruchtwasser (FW) untersuchte Neuraminsäure/Protein-Quotient (N/P-Q) ist ein Maß für den Sialinisierungsgrad von FW-Proteinen.

Ziel der Untersuchungen ist zu bestimmen, ob der N/P-Q im FW als Indikator für die fetale Reife dienen kann.

Material

Das untersuchte FW stammt von Frauen, die in 3 Gruppen eingeteilt werden. Gruppe 1 umfaßt 207 Frauen, die zwischen der 16.-21. Gestationswoche zur pränatalen Diagnostik genetischer Defekte kamen. 17 Frauen bei denen es zwischen der 28.-36. Gestationswoche zum partus praematurus kam, bilden die Gruppe 2. Alle Neugeborenen waren morphologisch unreif. Gruppe 3, das sind 101 Frauen, die termingerecht zwischen der 37.-42. Gestationswoche entbunden wurden. Ihre Neugeborenen waren morphologisch reif und gesund.

Bei Gruppe 1 wurde das FW durch transabdominale Amniozentese gewonnen, bei Gruppe 2 und 3 das nach dem Blasensprung vaginal abfließende FW aufgefangen.

Methode

Die Neuraminsäurebestimmung erfolgte mit einer modifizierten Methode nach Svennerholm und die Bestimmung der Proteine nach Lowry.

Ergebnisse und Diskussion

Tabelle 1 zeigt, daß besonders am Ende der Schwangerschaft höher sialinisierte Proteine im FW auftreten. Es ist anzunehmen, daß es sich hierbei um Sialoproteine vom Feten handelt, die mit zunehmender Reifung ins FW übertreten. Demzufolge wurde geprüft, ob der N/P-Q im FW als Indikator für die fetale Reife dienen kann. Als Entschei-dungskriterium zwischen reif und unreif wurde die untere Grenze des Referenzbereiches für Termingeborene (Tabelle 2) auf die FWProben der Früh- und Termingeburten ange-wendet.

Mit einer diagnostischen Spezifität von $97 \%$ bei einer diagnostischen Sensitivität von 88,2\% und einer Effizienz von 95,8\% ist der N/P-Q im FW als Mittel zur Beurteilung der fetalen Reife als gut einzuschätzen.

Freie Vorträge (Geburtshilfe)

112 
Tabelle 1. Der Neuraminsäure/Protein-Quotient im Fruchtwasser zu verschiedenen Zeiten der Schwangerschaft Median ( $\times$ ) und Quartile (25\% und 75\%). Prüfung auf Signifikanz mit dem UTest nach Mann und Whitney

$\begin{array}{llll}\text { Schwangerschaftswoche } & \mathrm{n} & \text { Neuraminsäure/Protein ( } \mu \mathrm{mol} / \mathrm{g}) \\ \text { Amniozentesen } & \times & 25 \% & 75 \%\end{array}$

$\begin{array}{llll}61 & 39,4 & 33,9 & 47,7\end{array}$

$82 \quad 37,9 \quad 35,3 \quad 43,7$

$27 \quad 39,3 \quad 36,1 \quad 43,8$

$16 \quad 38,2 \quad 35,8 \quad 42,0$

$14 \quad 39,0 \quad 35,1 \quad 41,3$

$\begin{array}{lllll}21 & 7 & 33,8 & 32,7 & 34,0\end{array}$

16-20 $200 \quad 39,0 \quad 34,4$

Frühgeburten

28-36 $17 \quad 42,4 \quad 40,1$

Termingeburten

37-42 $101 \quad 74,8 \quad 63,3$

44,1 i $\wedge$

$\times$

48,5

$>\times x$

85,2

$x=\mathrm{p}<0,05, x \times=\mathrm{p}<0,01, \mathrm{n}=$ Anzahl der Probanden.

Tabelle 2. Referenzbereiche bzw. 2,5-97,5 Perzentile für Neuraminsäure/Protein-Quotien-ten im Fruchtwasser zum Zeitpunkt der pränatalen Diagnostik (16.-20. Gestationswoche) und der termingerechten Geburt (37.-42. Gestationswoche) 